\title{
A FAMÍLIA COMO SUPORTE PARA O IDOSO NO CONTROLE DA PRESSÃO ARTERIAL ${ }^{1}$
}

\author{
THE FAMILY AS THE SUPPORT FOR CONTROLLING ANCIENT'S BLOOD PRESSURE
}

LA FAMILIA COMO AYUDA PARA ELANCIANO EN EL CONTROL DE PRESIÓN ARTERIAL

Francisca Elisângela Teixeira Lima* Marcos Venícios de Oliveira Lopes** Thelma Leite de Araujo****

RESUMO: O bjetivamos identificar os comportamentos dos familiares de idosos portadores de hipertensão arterial $(\mathrm{HA})$, frente à necessidade de monitoramento da pressão arterial e cumprimento da terapêutica farmacológica ou não. Trata-se de um estudo descritivo, desenvolvido no domicílio dos idosos matriculados em um Centro Assistencial para idosos, situado em Fortaleza-CE. Compôs a população um membro da família residente no endereço do idoso com HA, em um total de 18 participantes. Ao analisar os depoimentos encontramos como categorias: importância do idoso para família, constatando-se a presença de estreitos laços afetivos entre os familiares; participação da família no tratamento, observando-se que algumas famílias aderem ao tratamento dietético, juntamente com o idoso hipertenso; e influência da família nas modificações do estilo de vida, percebendo-se uma adesão da família às modificações no estilo de vida. Conclui-se que a família influencia no tratamento do idoso com HA, atuando como suporte para o autocuidado do idoso.

DESCRITORES: Família; Idoso; Hipertensão.

\section{INTRODUÇÃO}

Destacamos a importância da família, como suporte para o idoso, na adesão ao tratamento da hipertensão, visto que é o espaço indispensável à garantia da sobrevivência, de desenvolvimento e da proteção integral dos seus membros, além de propiciar os aportes afetivos e, sobretudo, materiais necessários ao desenvolvimento e bem-estar dos seus componentes. É no ambiente familiar que são absorvidos os valores éticos e humanitários, e onde se aprofundam os laços de solidariedade. É também em seu interior que se constróem as marcas entre as gerações e são observados valores culturais (Araujo et al., 1998).

Mediante a avaliação direta do ambiente familiar, a enfermeira poderá detectar, precocemente, problemas de saúde ou situações potencialmente geradoras dos mesmos. Pretendemos nos deter, neste estudo, nas doenças cardiovasculares, especificamente na hipertensão arterial, por ser uma doença silenciosa que atinge cerca de 15 a $20 \%$ da população adulta, além de se constituir um dos principais fatores de risco de morbidade e mortalidade cardiovasculares. A patologia, em referência, tem alto custo social, sendo responsável por cerca de $40 \%$ dos casos de aposentadoria precoce e de absenteísmo no trabalho em nosso meio (Consenso, 1998). Além disso, é responsável pela diminuição da expectativa de vida, bem como responde diretamente por $5 \%$ dos óbitos no grupo de doenças cerebrovasculares (Cordeiro et al., 1993).

P rocurou-se trabalhar com o idoso, por ser uma classe menos favorecida, dentro da sociedade, além de constituir um grupo em expansão, face ao aumento significativo de expectativa de vida. S egundo os últimos dados do IBGE, a população idosa, is to é, as pessoas acima de sessenta anos, representam hoje quase $8 \%$ da população total do país, correspondendo a mais de 11 milhões de pessoas idosas, dentre as quais $54 \%$ são mulheres (Silva, 1996). Esses dados revelam um crescimento do número de idosos, em decorrência de uma

\footnotetext{
Trabalho desenvolvido no projeto de pesquisa "Auto-ajuda nas alterações da pressão arterial". CNP q/ no: 520445/97-0

* Enfermeira. Especialista em Saúde da Família. Aluna do mestrado/UFC. CAPES. e-mail: felisangela@ uol.com.br

** Enfermeiro. Mestre em Enfermagem. Aluno do doutorado da Universidade Federal do Ceará. Bolsista da CAPES.

*** Doutora. Docente Adjunto do DENF/UFC. Coordenadora do Projeto. Pesquisadora do CNPq. e- mail: thelma@ufc.br
} 
série de fatores, dentre os quais podemos citar, primeiramente, o aumento da expectativa de vida do brasileiro, revelando uma melhoria das condições de vida desde o início do século. É interessante destacar que as mulheres têm uma expectativa de vida maior que a dos homens.

Mesmo tendo em vista este panorama, observa-se que o idoso não recebe a atenção que the é devida, mesmo dentro da sua própria família, sendo esse fato um reflexo da profunda representação negativa da velhice que a sociedade atual desenvolveu. 0 adjetivo "velho", desperta a sensação de algo fora de época e inútil. É assim que as pessoas idosas, algumas vezes, são vistas, principalmente, em função dos sinais de seus corpos, que determinam tais representações. Inexoravelmente, o passar dos anos vai impondo modificações no aspecto físico das pessoas, caracterizando o processo do envelhecimento. Infere-se daí, uma incapacidade física e mental generalizada para toda e qualquer atividade. Como conseqüência dessa discriminação, 0 isolamento social é uma característica evidente do idoso, cujo fim aterrador é a internação em asilos e o abandono da família.

No nosso cotidiano, parece claro o significado de família, tendo em vista que a maioria das pessoas fazem parte de uma unidade familiar. Porém, segundo Leonardo apud E Isen et al. (1994), a família se apresenta sob os mais variados tipos, ao exemplo da família nuclear, composta pelo pai, mãe e filhos, e da extensa ou ramificada, quando diferentes gerações são incluídas. Enquanto Cartana (1988), relata que algumas famílias incluem, entre seus membros, também as pessoas com as quais mantêm estreitos laços afetivos, já outras pessoas definem como família apenas seu círculo de amigos íntimos, sem nenhuma consangüinidade.

O estado de saúde da família envolve conhecimento, atitudes e valores, papéis e distribuição de tarefas. Para Bomar (1990), existe a necessidade de diferenciar o conceito de saúde da família e o de promoção da saúde familiar; sendo que saúde da família é mais do que a ausência de doença em um membro da família, isto é, inclui uma multiplicidade de variáveis biológicas, psicológicas, sociológicas, espirituais, dentro de um contexto cultural vivenciado pela família, enquanto sente bem-estar. Já promoção da saúde da família consiste nas ações desenvolvidas pela família para aumentar seu bem-estar ou sua qualidade de vida.

S egundo Ferrigno (1991), embora se possa argumentar que uma atitude positiva da família em relação ao idoso seja fundamental, é preciso, em primeiro lugar, constatar que muitos idosos não têm família ou mesmo tendo-as, com elas não convivem; daí que a responsabilidade, pelo idoso, é de toda sociedade. Em segundo lugar, é necessário perceber que quando se fala em família como suporte ao idoso, freqüentemente cai em uma visão paternalista do problema. Dessa forma, enxerga-se a família como necessária à sobrevivência dos velhos e ponto final. Um questionamento mais profundo sobre a imagem da velhice que cada familiar possui, certamente conduziria a uma reflexão acerca da própria família e do conjunto social. Isso implica em um processo de conscientização de nossas responsabilidades como agentes de transformação da sociedade, de modo a encararmos criticamente nossa prática, inserindo a família no tratamento do idoso, orientando-a quanto aos fatores de risco da hipertensão arterial.

Existem alguns fatores denominados de risco, que podem influenciar no aparecimento da $\mathrm{HA}$, os quais são organizados em dois grupos: congênitos, incluindo hereditariedade, sexo, raça e idade; e adquiridos, englobando: obesidade, hábito alimentar, uso do fumo, álcool e anticoncepcionais orais, além do estresse. Para uma correta abordagem junto ao indivíduo portador de hipertensão arterial, devemos considerar, além desses fatores de risco, as observações feitas por Dellácqua et al. (1997), que apontam uma gama de outros fatores, tais como: condição sócio-econômica, grau de instrução, atividade física, sentimento e conhecimento sobre a doença, crenças de saúde, estilo de vida, experiência anterior com a doença no meio em que vive, percepção da seriedade do problema, complexidade do tratamento, qualidade de assistência do sistema de saúde vigente, efeitos colaterais dos medicamentos, percepção social do problema e relacionamento inadequado com os membros da equipe de saúde.

Diversos autores confirmam a relação entre a elevação da pressão arterial e idade, sendo que níveis da PAS $>140 \mathrm{mmHg}$ e PAD>90 mmHg não devem ser considerados fisiológicos para o idoso. A elevação da PA, com a idade, é um fator bastante agravante, visto que o crescimento do grupo etário de 60 anos ou mais é significativo, estimando-se que, em 2025, haverá mais de 30 milhões de idosos no Brasil. A HA atinge cerca de $65 \%$ dos idosos em todo o mundo, podendo chegar a alcançar $80 \%$ das mulheres com mais de 75 anos (Consenso, 1998; Luna, 1989; R ibeiro; 1996). 
Diante do exposto, pretendemos identificar os comportamentos dos familiares de idosos portadores de hipertensão arterial, frente à necessidade de monitoramento da pressão arterial e de cumprimento da terapêutica farmacológica e não farmacológica, além de verificar as práticas de autocuidado promovidas pelos familiares dos idosos para as alterações no estilo de vida.

\section{MATERIAL E MÉTODOS}

Trata-se de um estudo descritivo, desenvolvido no domicílio dos idosos matriculados em um Centro Assistencial para pessoas da terceira idade, situado na cidade de Fortaleza-CE, no período de novembro de 1999 a janeiro de 2000. Trabalhamos com a visita domiciliar, por ser um instrumento para conhecer 0 ambiente familiar que influi na saúde de quem nela vive (Lizancos, 1994).

A população constituiu-se por um membro da família residente no mesmo endereço de cada idoso com diagnóstico de hipertensão arterial, matriculado no referido centro, fazendo acompanhamento em um sistema de saúde.

A amostra constou de 18 integrantes da população que se encontravam em casa no momento da visita domiciliar e que concordaram em participar do estudo. A participação voluntária foi confirmada, mediante 0 preenchimento de um termo de consentimento, após ter sido garantido o sigilo de suas identidades e facultado o direito de não mais participar do estudo quando achassem conveniente.

Dentre os métodos de coleta de dados, selecionamos o auto-relato que, segundo Polit \& Hungler (1995), favorece a coleta, pelo pesquisador, de grande quantidade de informações por meio do questionamento direto de pessoas. Utilizou-se um roteiro com perguntas abertas e/ou fechadas, garantindo a cobertura de todas as áreas de indagação, evitando desvios na obtenção dos dados.

Para análise dos resultados, percorremos os caminhos do método de análise de conteúdo de Bardin (1979). Inicialmente, realizamos uma leitura globalizada do material, e posteriormente dividimos partes para categorizar e classificar, com o intuito de decodificar o significado de trechos, correlacionando com o todo.

Os aspectos éticos da pesquisa foram respeitados, tendo o estudo, em questão, sido realizado com autorização dos coordenadores da instituição. Foi assegurada, a cada participante, a opção de participar ou não do estudo, e ainda a preservação da sua identidade, por meio de denominações como FC1 (família do cliente 1), FC2, FC3 até FC18.

\section{ANÁLISE DOS RESULTADOS}

Os resultados foram organizados em três categorias, constituídas da seguinte forma: importância do idoso para a família; participação da família no tratamento; e influência da família nas modificações do estilo de vida, atuando como suporte para o autocuidado.

IMPORTÂNCIA DO IDOSO PARA A FAMÍLIA

Esta categoria é destacada nas falas:

"Ela é responsável por tudo, não deixa faltar nada, mas somos nós (família) que cuidamos da casa para poupá-la ... ela só passeia, vai à casa dos amigos...não tem obrigações (FC3)."

"Ela é tudo para nós, porque só somos nós três (eu, minha irmã e ela). Toda responsabilidade de casa é dela. É ela que se preocupa comigo, me dá comida, roupas...(FC 7)."

"Mãe é uma coisa que a gente perde e nunca mais encontra, para mim ela é tudo, é a riqueza que eu tenho... filho e marido a gente acha outros... se ela morrer, eu morro...às vezes eu me aborreço com ela, mas é porque estou na menopausa ... (FC12)."

"A mãe é que ajuda em casa, porque eu e meu marido, a gente trabalha fora, então, ela faz o almoço, vai deixar minha filha no colégio ... mas tem um menino que ajuda ela em casa (FC14)." 
Diante dos depoimentos, constatamos a presença de estreitos laços afetivos entre os membros da família, salientando a importância do idoso dentro do grupo familiar, até mesmo porque o mesmo contribui com a sua aposentaria para o sustento da casa e auxilia nos afazeres domésticos, dentre outras funções, podendo interferir de modo satisfatório ou insatisfatório na sua adaptação à terapêutica. Porém, vale salientar que alguns familiares excluem o idoso das atividades domésticas, deixando-o na ociosidade. Isso pode ser vis to como um fator negativo, tendo em vista que o sedentarismo ocasiona a obesidade, agrava as doenças coronarianas e resulta em deterioração física e em problemas de auto-estima relacionados à ociosidade.

Percebemos que o idoso é citado como uma das principais fontes de renda para manutenção das despesas do lar. Esse pode ser um fator relevante de valorização do idoso dentro de sua própria família, respondendo pela redução do número de idosos abandonados em asilos.

Podemos relatar que uma posição favorável do idoso em sua família passa pelo questionamento da totalidade social, implicando em um processo de conscientização de nossa responsabilidade como agentes de transformação da sociedade, de modo a encararmos criticamente a nossa prática. É claro que a conquista de melhores condições de vida para os idosos passa pela conquista de uma sociedade mais humana.

\section{PARTICIPAÇÃO DA FAMÍLIA NO TRATAMENTO}

Os familiares destacaram a necessidade da participação no tratamento, enfatizando a importância do apoio e da presença:

“É muito importante participar do tratamento, pois aí sabemos como está a saúde dele. A gente faz chá, acompanha às consultas e lembra de tomar o remédio, quando ele não toma o remédio ele fica se sentido mal, mas ele esconde que é pra gente não brigar (FC2)."

"A gente acompanha as consultas do médico da pressão e de seis em seis meses leva ela para Santa Casa de Misericórdia, porque ela tem o coração crescido e isso muito nos preocupa. A gente ajuda para não ter aborrecimentos, acompanha o tratamento e lembra do remédio (FC3)."

"Minha irmã faz a alimentação como o médico manda, e quando minha avó está com moleza e não pode fazer nada, minha irmã faz chá e cuida dela (FC7)."

“...lembro ela de tomar os remédios, às vezes vou às consultas ... hoje a gente cuida mais dela ... quando ela tem cansaço passo a noite acordada cuidando dela ... porque meu avô morreu há 2 anos do coração e Deus me livre se ela morrer também ... (C11)."

Percebemos, por meio dos depoimentos, que a família não é um recipiente passivo do cuidado profissional, mas sim um agente, sujeito do seu próprio processo de viver.

É interessante observar que algumas famílias aderem ao tratamento dietético, juntamente com o idoso hipertenso, sendo um fator positivo bastante relevante para a saúde pública, pois assim estamos evitando, posteriormente, a elevação da PA, tendo em vista a presença do fator de risco hereditariedade, que poderá desencadear a HA se acrescido de fatores ambientais, como estresse e hábitos alimentares inadequados.

A saúde da família é melhor compreendida quando conhecemos situações concretas vivenciadas em seu cotidiano, surgindo a necessidade de compreendê-las como unidade de cuidado profissional. Por conta disso, devemos buscar novas estratégias, capazes de abranger todo o processo de assistir e cuidar da família, enfatizando a promoção da atenção primária e redução da necessidade de utilizar os setores terciários públicos, já que os mesmos, enfrentam uma superlotação, devendo dar prioridade aos casos mais graves.

Portanto, a família já não pode ser vista apenas como aquela que deve cumprir as determinações dos profissionais de saúde. Mais do que isso, ao ser reconhecida, assume a responsabilidade pela saúde de seus membros, a família precisa ser ouvida em suas dúvidas, a sua opinião deve ser levada em consideração, e, principalmente, sua participação deve ser incentivada em todo o processo profissional de cuidado.

Envolvendo a família no tratamento, os profissionais de saúde poderiam incentivar o acompanhamento dos familiares às consultas, evitando depoimentos como os que se seguem: 
"Nunca fiz nada no tratamento, ela mesma toma os remédios, vai às consultas... ela se cuida sozinha (FC1)."

"Eu só tenho ela, mas gosto de sair e me divertir com meus amigos, aí ela fica reclamando que eu só dou preocupação ... ela se cuida sozinha, não sei o horário dela tomar os remédios e nunca vou às consultas com ela porque ela vai de madrugada. Também não me preocupo nem com a minha saúde imagine com a dela (FC7)."

Observamos, nessas falas, que algumas famílias não se sentem com nenhuma responsabilidade diante do tratamento do idoso. Cuidar da família é bem mais complexo do que se imagina, pois envolve compreendêla em sua totalidade. Essa constatação faz crer que trabalhar no ambiente domiciliar é vantajoso, por permitir conhecer a realidade da família, porém há uma invasão de espaço, nem sempre aceito por todos. Dentro desse contexto, a enfermagem precisa atuar nos tratamentos da hipertensão, abordando a família, no sentido de esclarecer, participar, ajudar e negociar, utilizando diversos componentes do cuidar, levando em consideração que a família também é cuidadora, tendo sua própria visão de saúde, doença e cuidado.

\section{INFLUÊNCIA DA FAMÍLIA NAS MODIFICAÇÕES DO ESTILO DE VIDA}

A influência da família nas modificações do estilo de vida pode ser constatada nas seguintes falas:

"Eu como o que ela fizer, não tem problema se for insosso. Só que eu dou muita perturbação à ela, porque eu bebo e boto boneco no meio da rua ... não consigo parar de beber (FC1)."

“... tento impedir dele fumar e beber, mas não tem jeito, só conseguimos diminuir a quantidade de cigarro, que antes ele fumava uns 10 cigarros, agora ele fuma um ou dois por dia, e a bebida a gente tenta evitar, mas ele sai e bebe com os vizinhos (FC2)."

"Ela tem que fazer regime, mas ela não faz, a gente dá conselho, mas ela não segue, ela come muito. Às vezes a gente convida para ir fazer caminhada, mas ela tem preguiça e não tem que faça ela ir. Nós somos muito unidos, nos preocupamos um com o outro, quando um está doente damos toda atenção. Fazemos de tudo para ela controlar a pressão (FC4)."

"Depois que descobrimos que ela tinha pressão alta, começamos a tentar fazer uma dieta saudável para todos, mas como o ganho é pouco não dá para fazer muita coisa para melhorar a alimentação (FC7)."

"A gente deve ter cuidado com a alimentação, mesmo com saúde, porque se ela tivesse se cuidado antes do AVC, talvez tivesse evitado... eu tive eclâmpsia e poderia ter evitado se soubesse que eu tinha pressão alta (FC12)."

Percebemos, nesses depoimentos, que alterações na saúde de um membro, influenciam no estilo de vida de toda a família, sendo que o apoio permite ao indivíduo doente uma maior adesão ao tratamento, possibilitando sua reabilitação e/ou recuperação da saúde. 0 inverso também é observado nas falas do familiar do $\mathrm{C} 1$, quando destaca a agressividade como uma forma comum de afetar a integridade física ou emocional de seus membros.

O bserva-se, ainda, a existência de interação entre os membros da família e segundo E Isen et al. (1994), na interação, cada indivíduo é um sistema pessoal com seus valores, experiências, crenças, conhecimentos, necessidades, objetivos e percepções que influenciam numa situação. Essa interação é manifestada por condutas verbais e não verbais, sendo, ainda, orientada para o alcance dos seus objetivos, no caso é controlar a PA e elevar a qualidade de vida.

Toda família tem uma história, dentro da qual é estabelecido um nível de relacionamento com o ambiente, modificando-o e sendo modificado por ele. Entretanto, levadas em conta razões circunstanciais, a família tem várias possibilidades de encontrar soluções e vários caminhos para seguir e atingir seus objetivos. As pessoas que não compõem o grupo familiar, mas que com ele mantêm algum tipo de relação, são fontes de 
enriquecimento, de sustento em caso de dificuldades e, às vezes, até de conflitos, sendo possível a utilização desses recursos como forma de aumentar suas potencialidades.

\section{CONSIDERAÇÕES FINAIS}

Analisando a importância do idoso para a família observou-se a presença de estreitos laços afetivos entre os membros da unidade familiar. Esses tantos podem ser decorrentes de verdadeiros sentimentos, como da contribuição financeira que o idoso oferece para manutenção do lar ou, ainda, da colaboração nos afazeres domésticos.

Quanto à participação dos familiares no tratamento do idoso, estes destacaram a necessidade de maior apoio e da presença constante no tratamento, com acompanhamento às consultas, utilizando medidas alternativas, lembrando os horários da medicação, incentivando as alterações necessárias no estilo de vida, até mesmo aderindo conjuntamente ao tratamento. Entretanto, há de se notar que, ainda, existem famílias totalmente alheias ao tratamento do idoso.

Finalmente, em relação à influência da família nas modificações do estilo de vida, constatamos no grupo estudado, que a família costuma aderir ao tratamento, juntamente com o idoso, incentivando sua reabilitação e/ou recuperação da saúde.

ABSTRACT: Our goal's to identify the family members' behavior of families that has hypertensive ancient people, releting it to the need of bllod pressure monitoring with or without following the medicines procedure. It's a descriptive study, developed in the homes of ancient inscripted on a Assistencial Center for the old, in FortalezaCE. One family member that lives with a hypertensive ancient is picked to form the population used, in a total of 18 participants. During the speeches analysis, it was found as categories: ancient importance to the family, noticing the close relationship inside the family; family's participation on the treatment, seeing that some families adopt a treatment based on a diet; and life style's change influenced by the family, noticing the family participation on the life style. It comes to conclusion that the family has a direct influence on the therapeutic treatment of the hypertensive ancient, acting as a support to the ancient selfcare.

KEY WORDS: Family; Aged; Hipertension.

RESUMEN: Los objetivos del estudio fueron: identificar los comportamientos de los familiares de ancianos portadores de hipertensión arterial (HA), frente a la necesidad de monitorización de la presión arterial y cumplimiento, o no, de la terapia farmacológica. Se trata de un estudio descriptivo, desarrollado en el domicilio de los ancianos inscritos en un Centro Asistencial para ancianos, situado en Fortaleza-Ceará. Compone la población in miembro de la familia residente en el domicilio del anciano con HA, con un total de 18 participantes. Al analizar las declaraciones definimos como categorías: importancia del anciano para la familia, constatándose la presencia de estrechos lazos afectivos entre los familiares; participación de la familia en el tratamiento, observándose que algunas familias se suman al tratamiento dietético del anciano hipertenso; y influenza de la familia en las modificaciones del estilo de vida, percibiéndose una adhesión de la familia en las modificaciones del estilo de vida. Concluyese que la familia influencia directamente en lo tratamiento terapéutico del anciano con $\mathrm{HA}$, actuando como ayuda para el auto-cuidado del anciano.

PALABRAS CLAVE: Familia; Anciano; Hipertensión.

\section{REFERÊNCIAS}

1 ARAUJ O, T. L. et al. Reflexo da hipertensão arterial no sistema familiar. Rev. Soc. Cardiol. Est. São Paulo, v.8, n.2, supl A, p.1-6, mar/abr, 1998.

2 BARDIN, L. Análise de conteúdo. Lisboa: Edições 70, 1977.

3 BOMAR, P.J. Perspectives on family health promotion. Fam. Comm. Health, Rockville, v.12, n.4, p.1-11, 1990. 
4 CARTANA, M.H.F. Rede e suporte social das famílias. Florianópolis, UFSC, 1988. 157p. Dissertação (Mestrado em Enfermagem) - Curso de Mestrado em Enfermagem, Universidade Federal de Santa Catarina, 1988.

5 CONSENSO Brasileiro de hipertensão arterial III - serviço de educação médica continuada. Hoeschst Marion Rousset. Campos do J ordão, SP - 12 a 15 de fevereiro. 38p. 1998.

6 CORDEIRO, R. et al. Ocupação e hipertensão. Rev. Saúde Pública. São Paulo, v.27, p. 380-387, 1993.

7 DELLÁCQUA, M.C.Q. et al. Comunicação da equipe multiprofissional e indivíduos portadores de hipertensão arterial. Rev. Latino-am.Enferm. Ribeirão P reto, v.5, n.3, p.43-48, jul. 1997.

8 ELSEN, I. et al. Marcos para a prática de Enfermagem com famílias. Florianópolis: Ed. da UFSC, 1994. 194p.

9 FERRIGNO, J.C. Uma visão histórica de família e velhice. A terceira idade. v.4., n.4. São Paulo. SESC. jul. 1991.

10 LIZANCOS, F.M. A visita a domicílio. Generalidades. In. MARTIN, I. L. Atención domiciliaria. Diagnósticos de enfermeria. Madrid: McGraw-Hill-Interamericana de España, 1994. p.1-60.

11 LUNA, R. L. Hipertensão arterial. R io de J aneiro: MEDSI, 1989.

12 POLIT, D. F.; HUNGLER, B. P. Fundamentos de pesquisa em Enfermagem. 3. ed., Porto Alegre: Artes Médicas, 1995.

13 RIBEIRO, A. B. Atualização em hipertensão arterial: Clínica, diagnóstico e terapêutica. São Paulo: Atheneu, 1996.

14 SILVA, M. A. M. O. Velhos de rua no Brasil: a morte silenciosa. A Terceira Idade, São Paulo, v.9, n.19, p.35-43. Out. 1996. 